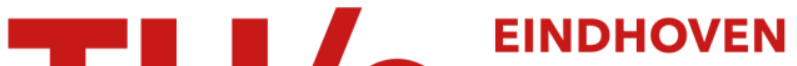

\section{Modal shift implications of e-bike use in the Netherlands: moving towards sustainability?}

\section{Citation for published version (APA):}

Sun, Q., Feng, T., Kemperman, A. D. A. M., \& Spahn, A. (2020). Modal shift implications of e-bike use in the Netherlands: moving towards sustainability? Transportation Research Part D: Transport and Environment, 78, [102202]. https://doi.org/10.1016/j.trd.2019.102202

\section{Document license:}

TAVERNE

DOI:

10.1016/j.trd.2019.102202

\section{Document status and date:}

Published: 01/01/2020

\section{Document Version:}

Publisher's PDF, also known as Version of Record (includes final page, issue and volume numbers)

\section{Please check the document version of this publication:}

- A submitted manuscript is the version of the article upon submission and before peer-review. There can be important differences between the submitted version and the official published version of record. People interested in the research are advised to contact the author for the final version of the publication, or visit the $\mathrm{DOI}$ to the publisher's website.

- The final author version and the galley proof are versions of the publication after peer review.

- The final published version features the final layout of the paper including the volume, issue and page numbers.

Link to publication

\section{General rights}

Copyright and moral rights for the publications made accessible in the public portal are retained by the authors and/or other copyright owners and it is a condition of accessing publications that users recognise and abide by the legal requirements associated with these rights.

- Users may download and print one copy of any publication from the public portal for the purpose of private study or research.

- You may not further distribute the material or use it for any profit-making activity or commercial gain

- You may freely distribute the URL identifying the publication in the public portal.

If the publication is distributed under the terms of Article 25fa of the Dutch Copyright Act, indicated by the "Taverne" license above, please follow below link for the End User Agreement:

www.tue.nl/taverne

Take down policy

If you believe that this document breaches copyright please contact us at:

openaccess@tue.nl

providing details and we will investigate your claim. 


\title{
Modal shift implications of e-bike use in the Netherlands: Moving towards sustainability?
}

\author{
Qi Sun ${ }^{\mathrm{a}, *}$, Tao Feng ${ }^{\mathrm{b}}$, Astrid Kemperman ${ }^{\mathrm{b}}$, Andreas Spahn \\ ${ }^{a}$ Department of Industrial Engineering \& Innovation Sciences, Eindhoven University of Technology, 5600 MB Eindhoven, the Netherlands \\ ${ }^{\mathrm{b}}$ Department of the Built Environment, Eindhoven University of Technology, the Netherlands
}

\section{A R T I C L E I N F O}

\section{Keywords:}

E-bike

Cycling

Modal shift

Panel data

\begin{abstract}
A B S T R A C T
This paper investigates the modal shift patterns of e-bike users in the Dutch context. We focus on the change in e-bikers' travel behavior to assess whether this change benefits sustainability. Our study provides direct ecologically valid evidence on modal shift by using a longitudinal dataset from the Netherlands Mobility Panel survey. We examine e-bikers' modal shift patterns before and after acquiring an e-bike. The findings indicate that after e-bike adoptions, conventional bike use reduces significantly, while car use reduces less strongly. Nonetheless, the share of car kilometers is much larger than that of conventional bikes at the baseline. Besides, the emission rate per passenger kilometer of an e-bike is several times lower than that of a car. These imply a net environmental gain after e-bike adoptions. The present study also sheds light on modal shifts at a disaggregated level by investigating those e-bikers who are more likely to drive less after ebike adoption. The findings suggest that e-bikers younger than 50 and those around retirement age (60-69) seem more likely to step out of their cars. Additionally, people living in rural areas tend to be more likely to reduce their car use than their counterparts in highly urbanized areas. Based on our findings, we present policy recommendations for achieving a greener shift in mobility systems.
\end{abstract}

\section{Introduction}

Humanity is facing major challenges such as climate change. After the energy industries, the transport sector is the second biggest source of greenhouse gas (GHG) emissions in the European Union (EU), contributing to about one-fifth of the total emissions (Eurostat, 2017). Within the transport sector, road transport accounts for the majority (72\%) of $\mathrm{CO}_{2}$ emissions (European Commission, 2016). Indeed, road transport is one of the few sectors where emissions have been rising rapidly over the last 20 years, with passenger cars alone responsible for about $12 \%$ of the EU's $\mathrm{CO}_{2}$ emissions (European Commission, 2017). Meanwhile, another trend is remarkable in the transport sector. With rapid growth in production, especially since the 2000 s (Weiss et al., 2015) and an estimated 35 million units sold in 2015 worldwide (Electric Bikes Worldwide Reports, 2016), electric bikes represent the most rapid uptake of alternative fueled vehicles in the history of motorization (Fishman and Cherry, 2016). It is thus worth investigating the implications of e-bikes for sustainable mobility.

Hopes are high that e-bikes can play a role in decarbonizing road transport, reducing air and noise pollution, and easing traffic congestion. Nevertheless, a pre-condition for these benefits is the assumption that people will shift from driving a car to riding an ebike. Reality, however, does not always guarantee a transition to sustainability, but presents a mixed picture of modal shifts from cars

\footnotetext{
* Corresponding author.

E-mail address: q.sun@tue.nl (Q. Sun).
} 
to e-bikes, from public transit to e-bikes, from conventional bicycles (c-bikes) to e-bikes, as well as from e-bikes to cars (Cherry et al., 2016; Kroesen, 2017). In a life cycle assessment of production processes and use phase, Cherry et al. (2009) quantify the environmental effects per passenger kilometer of e-bikes and compare that with other transport modes. Their results show that e-bikes lie in the middle of a sustainability spectrum among various transport modes. Researchers agree that the user modal shift pattern is a critical factor in terms of e-bikes' net environmental benefits (Wolf and Seebauer, 2014). It is important to gain further insights into the modal shift directions before moving on to unconditionally embracing e-bikes and promoting their use, as the environmental implications depend on the modes that are replaced.

This study aims to paint a nuanced picture of e-cycling and its modal shift implications in the Dutch context, one of the largest ebike markets in the world (Fishman and Cherry, 2016). A recent study measured e-bikes' substitution of other modes by comparing travel behavior patterns of e-bike owners with those of non-owners, using Dutch mobility survey data (Kroesen, 2017). The crosssectional data, however, does not allow a direct measurement of people's modal shift behavior before and after using e-bikes. For this reason, our study aims to directly assess e-bikers' behavior by applying the longitudinal Netherlands Mobility Panel (MPN) dataset (Hoogendoorn-Lanser et al., 2015), which has been collected since 2013.

The actual modal shift of various transport modes to e-bikes differs depending on local contexts. For instance, the substitution of cars by e-bikes in Austria is mainly done for leisure purposes and rarely for commuting (Wolf and Seebauer, 2014). In the Netherlands, little is known about modal shift patterns for various trip purposes, including commuting, shopping, leisure, and transporting people or goods. According to the Netherlands Institute for Transport Policy Analysis (KiM, 2016), commuter trips account for onethird of total passenger kilometers, thus contributing disproportionately to traffic congestion and environmental pollution due to their non-discretionary nature (Heinen et al., 2010). In terms of sustainable mobility, a major challenge is to change the most habitual types of travel, like daily commute (Fyhri and Fearnley, 2015). Leisure trips also form a substantial part of the total kilometers traveled by people in the Netherlands (KiM, 2016). Therefore, we need to consider the substitutional effects of e-bikes on trips for various purposes, especially commuting and leisure.

Existing research mostly analyses the modal shift effects at an aggregate level. Hardly any insight is available at an individual level on what factors influence a green shift away from the car. To address this gap, we aim to identify the groups of people who are more likely to substitute their car use. We thus examine how social-demographic factors relate to the change in car use after adopting an e-bike. It is particularly interesting to discover the characteristics of people likely to shift from carbon-intensive modes to e-bikes. If e-bike policy targets the right people, the change in travel behavior could achieve more sustainability benefits.

Our main aim in investigating e-bikers' modal shift behavior is to assess the environmental implications. We start by reviewing research on modal shifts to e-bikes in various countries. Then we discuss our application of the data, followed by the results of our analyses. Based on the findings, the final section presents conclusions and policy recommendations for future research.

\section{Background}

Alongside an exponential growth in the e-bike market and use, an increasing amount of research has been published on e-bikes since the early 2000s. A highly pertinent topic is e-bikes' substitutional effects (Fishman and Cherry, 2016). Table 1 presents the main outcomes of research on modal shift patterns in different parts of the world ${ }^{1}$.

A general pattern emerging from the overview in Table 1 is that the modal shift largely depends on available transport alternatives in a given local context (Kroesen, 2017). Where public transit constitutes a large share of travel, notably in Chinese cities, a large proportion of e-bike users have shifted from public transit, particularly buses. The substitution of c-bikes with e-bikes is prominent in countries where cycling already accounts for a substantial share of trips, such as the Netherlands and Denmark. In areas with low cycling levels like North America and Australia, there is a more prominent transition from car travel to e-cycling. This pattern is in line with findings by Haustein and Møller (2016), namely a higher replacement of trips formerly made by c-bike in countries with higher cycling levels, compared to countries with no specific cycling culture. This may be because countries where cycling is marginal have a much larger proportion of highly equipped and training-oriented cyclists. For this subgroup of cyclists, an e-bike contradicts their motivation for cycling: a means of exercise. Thus, Fyhri et al. (2017) argue that an e-bike is of little interest to some who already cycle a lot, or intend to cycle more, but is more appealing to those who want to drive less.

For the Dutch case, some existing research findings seem to be inconsistent. A study by Lee et al. (2015) indicates that e-bikes replace c-bike trips and car trips to a similar extent; Kroesen (2017) shows that e-bikes more prominently substitute c-bike travel than car travel. On the other hand, a study by Jones et al. (2016) concludes that the substitution depends on the main travel mode before ebike adoption. Given that the car is a more dominant mode than the c-bike in the Netherlands, one would expect a greater reduction in car trips than c-bike trips. By mapping people's travel patterns before and after adopting an e-bike (see Fig. 2), this study contributes to the literature, adding direct evidence to the debate. Additionally, we aim to provide a better understanding of modal shift patterns for various travel distances and purposes (see Tables 5 and 6). Furthermore, as little is known about the profile of people more likely to reduce their car use after adopting an e-bike, our research also sheds light on this aspect (see Table 7).

\section{Data collection}

To answer the research questions, we use the Netherlands Mobility Panel (MPN) data. Starting in 2013, the Netherlands Institute

\footnotetext{
${ }^{1}$ For similar literature overview, please refer to (Kroesen, 2017).
} 
Table 1

Overview of modal shifts in e-bike use around the world.

\begin{tabular}{|c|c|c|c|}
\hline Region & Scope of the research & Modal shift results & Source \\
\hline \multirow{3}{*}{ Netherlands } & $\begin{array}{l}\text { 104,239 samples from Dutch Mobility Survey } \\
\text { comparing e-bikers \& non-users' travel modes }\end{array}$ & $\begin{array}{l}\text { E-bike ownership greatly reduces use of c-bikes, and to a } \\
\text { lesser extent, car/public transit use }\end{array}$ & Kroesen (2017) \\
\hline & $\begin{array}{l}\text { Questionnaire } 217 \text { e-bikers via online link, mail } \\
\text { and snowball method }\end{array}$ & $\begin{array}{l}\text { For } 68 \% \text { respondents, e-bikes replace c-bike trips; for } \\
62 \% \text {,short car trips; for } 45 \% \text { short public transit trips, and for } \\
18 \% \text {, walking }\end{array}$ & Lee et al. (2015) \\
\hline & $\begin{array}{l}22 \text { adult e-bike owners ( } 12 \text { in NL and } 10 \text { in UK) } \\
\text { recruited through opportunity sampling }\end{array}$ & $\begin{array}{l}\text { People who mainly used c-bikes, report lower c-bike use after } \\
\text { e-bike purchase; for those who mostly drove, reduction in car } \\
\text { use is more prominent after e-bike purchase }\end{array}$ & Jones et al. (2016) \\
\hline Denmark & $\begin{array}{l}\text { Questionnaire } 427 \text { randomly selected } \\
\text { respondents using an e-bike regularly over a } \\
\text { period of at least } 1 \text { month }\end{array}$ & $\begin{array}{l}64 \% \text { use e-bike on trips when otherwise use c-bike; } 49 \% \text { when } \\
\text { normally use car (bus: } 48 \% \text {; walk: } 33 \% \text {; train/metro: } 26 \% \text { ). } \\
\text { Remarkably, } 37 \% \text { bought an e-bike to replace a household car }\end{array}$ & $\begin{array}{l}\text { Haustein \& Møller } \\
\text { (2016) }\end{array}$ \\
\hline Sweden & $\begin{array}{l}\text { Questionnaire } 321 \text { respondents who purchased } \\
\text { e-bikes through one retailer }\end{array}$ & $\begin{array}{l}\text { E-bikes replace } 47 \text { to } 67 \% \text { of car trips, } 15 \text { to } 26 \% \text { c-bike trips, } \\
4 \text { to } 16 \% \text { public transit trips and } 3 \text { to } 12 \% \text { walking trips }\end{array}$ & $\begin{array}{l}\text { Winslott Hiselius \& } \\
\text { Svensson (2014) }\end{array}$ \\
\hline Austria & $\begin{array}{l}\text { Survey } 1398 \text { experienced e-bikers in } 4 \text { provinces } \\
\& 4 \text { cities over Oct } 2011 \text { (retrospective to reduce } \\
\text { seasonal effect) }\end{array}$ & $\begin{array}{l}\text { Early adopters mostly } 60 \text { and older, use e-bike for leisure } \\
\text { trips. E-cycling hardly substitutes carbon-intensive } \\
\text { commuting modes }\end{array}$ & $\begin{array}{l}\text { Wolf \& Seebauer } \\
(2014)\end{array}$ \\
\hline CHINA & $\begin{array}{l}\text { Intercept survey ( } 2216 \text { people) at bike-parking } \\
\text { facilities from } 2006 \text { to } 2012\end{array}$ & $\begin{array}{l}\text { E-bikes substitute } 50 \% \text { of bus trips, } 20-30 \% \text { c-bike trips, } 10 \% \\
\text { car trips }\end{array}$ & Cherry et al. (2016) \\
\hline \multicolumn{4}{|l|}{ Kunming } \\
\hline Shanghai & $\begin{array}{l}\text { Intercept surveys } 696 \text { users of 2-wheelers (c- } \\
\text { bike, e-bike, LPG scooter) }\end{array}$ & $\begin{array}{l}51 \% \text { e-bike users previously traveled by bus; } 18 \% \text { by c-bike, } \\
10 \% \text { walked, } 7 \% \text { subway, and } 8 \% \text { taxi/car }\end{array}$ & $\begin{array}{l}\text { Cherry \& Cervero } \\
(2007)\end{array}$ \\
\hline NORTH AMERICA & $\begin{array}{l}\text { Survey of } 1796 \text { e-bikers via social media } \\
\text { platforms, e-bike dealers and leaflet in the } \\
\text { Portland, OR, area. }\end{array}$ & $\begin{array}{l}\text { E-bike trips replaced } 45.6 \% \text { car trips, } 27.3 \% \text { active transport/ } \\
\text { public transit trips, } 25.3 \% \text { would not have been taken, and } \\
1.8 \% \text { other trips }\end{array}$ & $\begin{array}{l}\text { MacArthur et al. } \\
\text { (2018) }\end{array}$ \\
\hline AUSTRALIA & On-line survey of 529 e-bike users & $\begin{array}{l}60 \% \text { acquired e-bike to replace car trips; } 50 \% \text { for less effort; } \\
\text { half not considered alternative transport prior to e-bike } \\
\text { purchase; other half had considered, in descending order: } \\
\text { bike, public transit, motor-scooter }\end{array}$ & $\begin{array}{l}\text { Johnson \& Rose } \\
\text { (2013) }\end{array}$ \\
\hline
\end{tabular}

for Transport Policy Analysis (KiM) initiated the MPN. This panel consists of approximately 2500 households. Every year, one or more household members aged 12 years and older are asked to record a three-day travel diary. The travel information includes transportation modes, trip distances, duration, purpose, etc. Data is also collected on the socio-demographics of individuals and households, such as gender, age, education level, type of job, vehicle ownership, and household income level. This study looks at the surveys in 2013, 2014, 2015 and 2016. More details of the MPN data are available in Hoogendoorn-Lanser et al. (2015).

To assess the modal shifts before and after using an e-bike, our sample group consists of new e-bike owners, specifically those who did not own an e-bike in the baseline year (T0), but did own one the following year (T1). This enables us to compare individuals' travel patterns with their travel behavior in the baseline scenario. Note that T0 and T1 are individual specific, based on the year a person acquired an e-bike. We selected people who stated that they own an e-bike in the current year and recorded that they did not own an e-bike in the previous year. We further refined our sample by checking the travel diary. As this is a three-day travel sample, it is possible that an e-bike owner did not travel by e-bike during the surveyed period. To study the substitution effect, we therefore only selected people who made at least one trip by e-bike in the current year. Finally, a consistency check excluded those who did not state e-bike ownership but traveled by e-bike. In addition, to better profile the sample characteristics, a group of non e-bike owners from MPN 2015 were selected and compared with the sample in Table 2.

Our efforts stand out in two important ways. First, this study can directly assess the modal shift effects of e-bike use. Some studies apply a cross-sectional design, comparing e-bike users with non-users. However, the baseline travel patterns of e-bikers before they start using an e-bike are unknown. The e-bike user group probably already differs from the non-user group in the baseline scenario. Simsekoglu and Klöckner (2018) point out that we need to measure c-bike use and car use before and after the adoption of an e-bike in order to understand the impact on other travel modes. Our study addresses this research gap. Furthermore, we provide more detailed information than many prior studies that rely on retrospective surveys or experimental set-ups. Even though such studies deliver important insights, these two methods have some systematic shortcomings. Collecting data via retrospective surveys can lead to memory bias. There are also generalization problems, including loss of details that are difficult to recall from the past. Information such as distance and purpose of each trip is difficult for people to remember precisely. This study is thus unique given the reliability and richness of the panel data. Another common method is a field trial for people to test e-bikes for a certain period. However, experiments cannot guarantee actual travel patterns. Participants may take advantage of the limited window of e-bike access to fully explore the potential of this means of transport. In contrast, our research enjoys more ecological validity by gaining insights into real life practices of e-cycling (Fyhri and Fearnley, 2015). 
Table 2

Profiles of e-bikers in the sample $(\mathrm{N}=107)$ and non e-bike owners $(\mathrm{N}=5151)$.

\begin{tabular}{|c|c|c|c|}
\hline Variable & Category & E-bike Users (\%) & Non-Owners (\%) \\
\hline \multirow[t]{2}{*}{ Gender } & Female & 59.8 & 52.2 \\
\hline & Male & 40.2 & 47.8 \\
\hline \multirow[t]{6}{*}{$\mathrm{Age}^{* * * * *}$} & $12-39$ & 12.1 & 46.7 \\
\hline & $40-49$ & 26.2 & 18.0 \\
\hline & $50-59$ & 21.5 & 17.7 \\
\hline & $60-69$ & 25.2 & 10.2 \\
\hline & 70 and older & 15.0 & 7.5 \\
\hline & Employed & 53.3 & 54.6 \\
\hline Employment & Retired & 28.0 & 11.6 \\
\hline \multirow[t]{2}{*}{ Status } & Householder & 12.1 & 5.9 \\
\hline & Other & 6.5 & 28.0 \\
\hline \multirow[t]{3}{*}{ Education level* } & Low & 22.4 & 34.1 \\
\hline & Middle & 45.8 & 36.7 \\
\hline & High & 31.8 & 29.2 \\
\hline \multirow[t]{3}{*}{ Household Car Ownership } & No car & 13.1 & 14.0 \\
\hline & $1 \mathrm{car}$ & 50.5 & 47.2 \\
\hline & $2+$ cars & 36.4 & 38.8 \\
\hline \multirow[t]{3}{*}{ No. of $<12$ year old children in household } & No child & 85.0 & 79.1 \\
\hline & 1 child & 6.5 & 11.5 \\
\hline & 2 or more & 8.4 & 9.4 \\
\hline \multirow[t]{4}{*}{ Household Income Level* } & Low & 8.4 & 16.3 \\
\hline & Medium & 60.8 & 48.8 \\
\hline & High & 14.0 & 19.3 \\
\hline & Unknown & 16.8 & 15.6 \\
\hline \multirow[t]{5}{*}{ Urban Density } & Very highly urbanized & 15.9 & 17.7 \\
\hline & Highly urbanized & 29.0 & 28.8 \\
\hline & Moderately urbanized & 29.0 & 23.6 \\
\hline & Low urbanization & 17.8 & 20.1 \\
\hline & Non-urbanized area & 8.4 & 9.9 \\
\hline
\end{tabular}

NB: statistics for e-bike users are from the year (T1) people adopted an e-bike. Due to approximation, percentages may not add up to 100. Chi-square tests were applied to test for differences between e-bikers and non-owners.

$* \mathrm{P}<0.05$.

$* * * \mathrm{P}<0.001$.

\section{Results and analysis}

\subsection{Characteristics of e-bike users}

Across four MPN surveys (from 2013 to 2016), a total of 107 new e-bike users emerged from 98 households. It is not uncommon for two or more persons in the same household to acquire an e-bike. Table 2 lists the characteristics of our sample compared with a group of non e-bike owners from MPN 2015.

Table 2 shows that the sample is predominately middle and senior aged members of the population, thus consists of a higher share of retired persons. In particular, there are considerably fewer people younger than 40 in the e-biker group than in the non-owner group. Partly related to age, the share of retired people is larger in the e-bike user group, whereas the share of employed people is rather similar. Compared with the control group, the majority of the sample comes from households with medium income level. The proportion of people with middle educational level is larger while the share of low educational level is smaller. In terms of gender, the proportion of women in the sample group seems to be higher than in the control group, though this may not be generalized to the overall Dutch population due to the low significance level.

Regarding travel patterns, we compare the modal split by distance within the whole sample group before adopting an e-bike at T0 and that within the Dutch population (KiM, 2016). The overall pictures are similar (Fig. 1). The car km share is slightly higher (75\% vs. $72 \%$ ), and train $\mathrm{km}$ lower than the general population. We conclude that the sample is fairly representative of the Dutch population with regards to travel patterns.

\subsection{E-bike users' travel patterns}

Level of cycling is related to sociodemographic factors including gender and age as well as household characteristics such as car ownership (Garrard et al., 2008; Cervero et al.,2009; Heinen et al., 2010; Buehler et al., 2011). Table 3 presents the sample's e-cycling levels in relation to the three indicators. Men e-cycle significantly longer than women per average trip distance. Women travel almost twice as much per average trip distance when comparing their cycling by e-bike at T1 and their cycling by c-bike at T0. For men, their cycling distance experiences an increase of $47.4 \%$. This indicates that an e-bike is more of a distance boost for women than for men. In other words, the e-bike is a range leveler for women riding bicycles. There is no significant difference in e-bike km or number of e- 


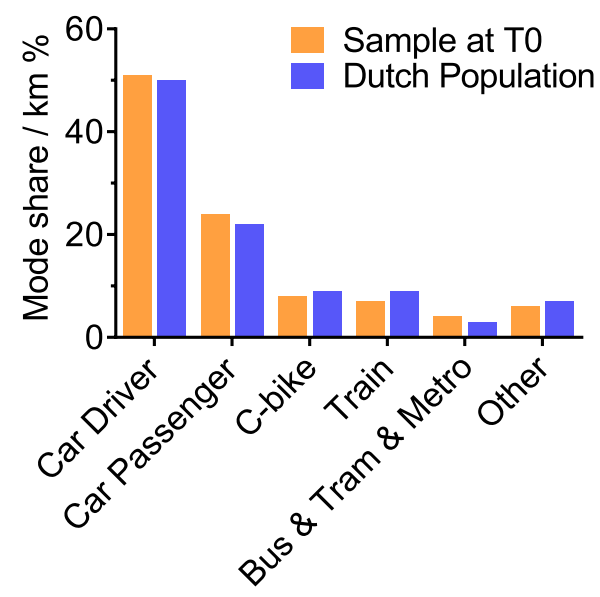

Fig. 1. Modal split in the sample (T0) and Dutch population.

Table 3

E-cycling of user groups.

\begin{tabular}{|c|c|c|c|c|}
\hline Variable & Category & E-bike $\mathrm{km} /$ person/day & E-bike trips/person/day & Average e-bike trip distance $(\mathrm{km})$ \\
\hline \multirow[t]{2}{*}{ Gender ${ }^{m+k e n}$} & Female & 5.5 & 1.5 & $3.8(0.25)$ \\
\hline & Male & 7.7 & 1.4 & $5.6(0.48)$ \\
\hline \multirow[t]{5}{*}{$\mathrm{Age}^{\text {inkt*x}}$} & 25-39 & 8.9 & 1.3 & $6.6(1.03)$ \\
\hline & $40-49$ & 6.8 & 1.4 & $5.0(0.43)$ \\
\hline & $50-59$ & 4.9 & 1.4 & $3.5(0.33)$ \\
\hline & $60-69$ & 7.5 & 1.6 & $4.7(0.55)$ \\
\hline & $70-79$ & 3.8 & 1.4 & $2.8(0.42)$ \\
\hline \multirow[t]{3}{*}{ Car Ownership } & No Car & 7.3 & 1.6 & $4.7(0.74)$ \\
\hline & $1 \mathrm{Car}$ & 7.0 & 1.5 & $4.6(0.34)$ \\
\hline & $2+$ Cars & 5.2 & 1.3 & $4.1(0.39)$ \\
\hline All Users & & 6.4 & 1.4 & $4.5(0.25)$ \\
\hline
\end{tabular}

NB: Standard errors of the mean in parenthesis. ANOVA and T-tests were applied to test for differences among categories of each variable; the tests show significant results only for the column of average e-bike trip distance $(\mathrm{km})$.

$* * * \mathrm{P}<0.001$; subsequently a Bonferroni post hoc test was performed after the F-test showed significant differences.

bike trips per day among different user groups. Average trip distance is an indicator for cycling intensity (Cairns et al., 2017; Krizek et al., 2009). A post hoc Bonferroni test, (which was performed after the F-test indicted a significant difference), shows that the 25$39 y$ and 40-49y are more active e-bikers than the 50-59y and 70-79y groups.

Regarding trip purposes, the majority of the e-bike trips are for commuting, shopping and leisure (Table 4). E-bikes are most frequently used for shopping (35.9\%), followed by leisure trips (25.5\%). It is worth noting that the average e-bike trip distance of commuting is significantly longer than that of other trip purposes. Thus commuting's km share is the highest despite its lower share in number of trips.

\subsection{Modal shift}

Fig. 2 shows the average modal split among the sample individuals before and after e-bike adoptions. As this study considers the environmental impacts of different transport modes, our comparison is based on kilometers traveled, instead of trip numbers. Since

\section{Table 4}

The purposes of e-bike trips.

\begin{tabular}{llll}
\hline Trip Purpose & Share of e-bike km (\%) & Share of number of trips (\%) & Average trip distance (km) \\
\hline Commuting & 39.3 & 20.7 & $8.5(0.61)$ \\
Shopping & 25.2 & 35.9 & $3.1(0.31)$ \\
Leisure & 26.5 & 25.5 & $4.6(0.55)$ \\
Transport people or goods & 5.2 & 10.2 & $2.3(0.29)$ \\
Other \& unknown & 3.8 & 7.6 & $2.2(0.33)$ \\
Total & 2055.8 & 459 & $4.5(0.25)$ \\
\hline
\end{tabular}

NB: Standard errors of the mean in parenthesis. T-tests were applied to test for differences among categories of each variable. $* * * \mathrm{P}<0.001$ 


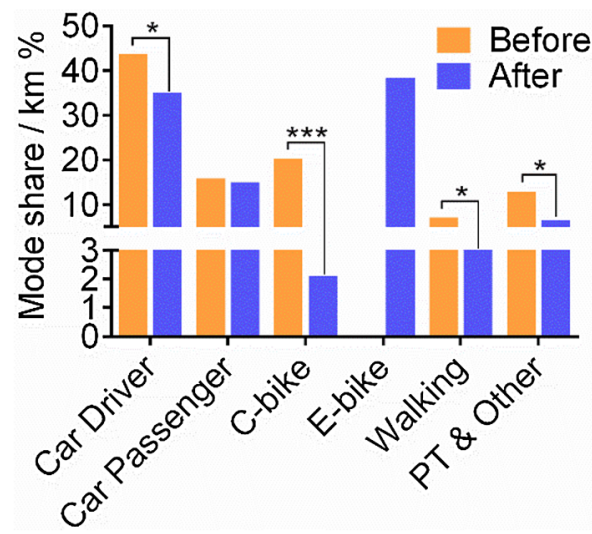

Fig. 2. Average modal split $(\mathrm{km} \%)$ per capita before and after acquiring an e-bike. $* \mathrm{P}<0.05$, ***P $<0.001$.

the sample is specifically selected from those who did not own or use an e-bike before adopting one, the e-bike kilometers in the "before" travel data are obviously zero. A paired-sample $t$-test was conducted to assess whether the changes in the before and after shares for each mode are significant. The results indicate that c-bike use reduces more significantly than that of car driving or walking. It is worth noting that, the change in car passenger share is not significant as the case for car driving. The car mode share drops by $16 \%$ despite still being the main mode of transport. Considering the total cycling level by e-bike and c-bike together, the share of cycling is almost doubled.

Social demographic variables are well documented as influencing transportation mode choices and travel behavior (Van Acker et al., 2010). Our before-after comparison covers a one-year difference in time, thus we would expect little change in social demographic attributes. Nevertheless, to avoid ruling out potential effects, we examine changes in personal characteristics. While everyone is one year older, their employment status, educational and household income levels, residence urbanization level, and number of families with young children ( $<12$ years old) remain mostly stable. The change in vehicle ownership is perhaps most remarkable. Along with the $100 \%$ increase in personal e-bike ownership, c-bike ownership drops from $81.3 \%$ to $43 \%$, which is shown to be statistically significant based on chi-square tests. This is particularly striking in a Dutch context, where c-bike ownership is so common that there are more c-bikes than inhabitants in the Netherlands (KiM, 2016). Household car ownership also changes. The sample's car ownership drops from $92.5 \%$ to $86.9 \%$. This indicates that e-bike ownership significantly substitutes c-bike ownership, but not much for car ownership. In contrast, research in a Chinese context shows that high e-bike ownership increases the likelihood of car purchase (Ling et al., 2015). Although this suggests e-bikes might not substitute cars on the motorization pathway in China, they might play a different role in a more established automobile country like the Netherlands. Nonetheless, a slight drop in car ownership does not necessarily imply stable car use and this study only examines the year directly after e-bike uptake. Due to high investment costs and the longevity of cars, changes in car ownership patterns might only be gradual. It is therefore perhaps too early to see whether the adoption of e-bikes would reduce car-ownership or prevent the acquisition of an extra car for the family in the long run. This could be an area for future research. In sum, apart from c-bike ownership, social demographic attributes stay mostly the same after acquiring an e-bike.

\subsection{Modal shift patterns per distance}

Table 5 shows interesting before-after changes once we break down all the trips into different distance levels. For trips shorter than $20 \mathrm{~km}$, around $40 \%$ are by e-bike after its adoption. While the c-bike is still used for some trips less than $5 \mathrm{~km}$, most short and

Table 5

Percentage of trip numbers per mode and distance before (B) and after (A) adopting an e-bike.

\begin{tabular}{|c|c|c|c|c|c|c|c|c|c|c|c|c|}
\hline \multirow{2}{*}{$\begin{array}{l}\text { Modes } \\
\text { Trip Distance (km) }\end{array}$} & \multicolumn{2}{|l|}{ Car } & \multicolumn{2}{|l|}{ C-bike } & \multicolumn{2}{|c|}{ E-bike } & \multicolumn{2}{|c|}{ Walking } & \multicolumn{2}{|c|}{ PT\&Other } & \multicolumn{2}{|c|}{ Total } \\
\hline & B & $A$ & B & $A$ & B & $A$ & B & $A$ & B & $A$ & B & $A$ \\
\hline$<5$ & $33.6^{*}$ & $27.6^{*}$ & $40.3^{x+2 k t)}$ & $6.9^{* \ldots+k k}$ & - & 47.6 & $23.0^{\text {*** }}$ & $16.4^{\text {k* }}$ & $3.0^{*}$ & $1.4^{*}$ & 699 & 720 \\
\hline 5-10 & $77.8^{k+k x+k}$ & $54.9^{* * * x}$ & $7.8^{* *}$ & $1.3^{* x / x}$ & - & 41.2 & 3.6 & 0.7 & $10.8^{\text {ktk }}$ & $2.0^{* * *}$ & 167 & 153 \\
\hline $10-15$ & $81.3^{k n t}$ & $57.3^{* *}$ & 4.2 & 0 & - & 33.3 & 2.1 & 1.3 & 12.5 & 8.0 & 48 & 75 \\
\hline $15-20$ & 67.6 & 63.4 & 10.8 & 0 & - & 36.6 & 0 & 0 & 21.6 & 0 & 37 & 41 \\
\hline$>20$ & 77.5 & 72.6 & 2.7 & 0 & - & 13.7 & 0 & 0 & 19.8 & 13.7 & 111 & 95 \\
\hline
\end{tabular}

NB: Significance difference between " $\mathrm{B}$ " and " $A$ " based on chi-square tests.

$* \mathrm{P}<0.05$.

$* * \mathrm{P}<0.01$.

$* * * \mathrm{P}<0.001$. 
Table 6

Modal split (km \%) per mode and trip purpose before (B) and after (A).

\begin{tabular}{|c|c|c|c|c|c|}
\hline & Commuting & Shopping & Leisure & Transport & Other \& Unknown \\
\hline B Car & $76.3^{\text {k⿻上丨 }}$ & 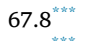 & $66.8^{k * *}$ & $86.7^{*}$ & $82.1^{* k * \%}$ \\
\hline A Car & $50.8^{* \ldots * *}$ & $50.6^{\text {*wek }}$ & $69.8^{* * *}$ & $82.7^{*}$ & $66.5^{* * * x}$ \\
\hline B C-bike & $9.0^{* x+k x}$ & $13.5^{k * * *}$ & $8.7^{* k * k}$ & $6.0^{3 \times k x}$ & 3.2 \\
\hline A C-bike & $0.1^{* * \times *}$ & $2.1^{\text {knkx }}$ & $0.8^{* \times+k}$ & $1.5^{* * \ldots}$ & 4.1 \\
\hline B E-bike & - & - & - & - & - \\
\hline A E-bike & 37.6 & 41.0 & 12.3 & 15.3 & 20.0 \\
\hline B Walking & 0.1 & $2.6^{* * *}$ & $4.6^{\text {vitex }}$ & 1.0 & $0.7^{* \cdots * x}$ \\
\hline A Walking & 0.0 & $1.0^{* *}$ & $2.1^{* * * k}$ & 0.5 & $3.1^{* * * *}$ \\
\hline B PT \& Other & $14.7^{* *}$ & $16.2^{k \ldots * *}$ & $19.9^{k \times \sqrt{k * k}}$ & 6.4 & $14.0^{\text {*k⿲丶丶 }}$ \\
\hline A PT \& Other & $11.4^{* *}$ & $5.3^{k+\cdots * x}$ & $15.0^{\text {tiknth }}$ & 0.0 & $6.3^{* * * *}$ \\
\hline B Total $(\mathrm{km})$ & 1734.13 & 1406.46 & 3462.99 & 1721.00 & 1598.70 \\
\hline A Total $(\mathrm{km})$ & 2151.83 & 1265.54 & 4414.07 & 698.51 & 393.95 \\
\hline
\end{tabular}

NB: Significance difference between "B" and " $A$ " based on chi-square tests.

* $\mathrm{P}<0.05$.

$* * \mathrm{P}<0.01$.

$* * * \mathrm{P}<0.001$.

Table 7

Regression model for change in e-bikers' $(\mathrm{N}=107)$ car mode share.

\begin{tabular}{|c|c|c|c|c|}
\hline Model & Unstandardized Coefficients & Std. Error & Standardized Coefficients & Sig. \\
\hline (Constant) & -0.306 & 0.180 & & 0.093 \\
\hline \multicolumn{5}{|l|}{ Age $(r e f=50-59)$} \\
\hline $25-39$ & -0.371 & 0.165 & -0.244 & 0.027 \\
\hline $40-49$ & -0.305 & 0.133 & -0.270 & 0.024 \\
\hline $60-69$ & -0.295 & 0.139 & -0.255 & 0.037 \\
\hline $70-79$ & -0.140 & 0.160 & -0.101 & 0.383 \\
\hline \multicolumn{5}{|c|}{$\begin{array}{l}\text { Urbanization Level } \\
\qquad(\text { ref }=\text { Non-urbanized })\end{array}$} \\
\hline Very highly urbanized & 0.198 & 0.198 & 0.146 & 0.320 \\
\hline Highly urbanized & 0.389 & 0.188 & 0.355 & 0.041 \\
\hline Mod. urbanized & 0.309 & 0.186 & 0.282 & 0.100 \\
\hline Low urbanization & 0.268 & 0.193 & 0.206 & 0.168 \\
\hline Average Trip Distance & 0.017 & 0.006 & 0.287 & 0.003 \\
\hline R-square & 0.186 & & 0.111 & \\
\hline
\end{tabular}

almost all c-bike trips longer than $5 \mathrm{~km}$ are by e-bike after adoption. When comparing c-bike trips before with e-bike trips after, ebikes boost cycling trips the most for distances ranging from 5 to $20 \mathrm{~km}$, indicating a range extender effect on cycling. In the case of car trips, interestingly, e-bikes prominently substitute 5 to $15 \mathrm{~km}$ trips more than the ones shorter than $5 \mathrm{~km}$.

\subsection{Modal shift patterns by trip purpose}

To determine modal shift patterns, we also examine trips by different modes, for commuting, shopping and leisure purposes at trip level for the whole sample group (see Table 6). The total distances traveled decrease by $10.1 \%$, while there are more fluctuations in the distances for various trip purposes. Shopping trip kilometers are the most stable one, dropping only by $10.2 \%$. Leisure trip kilometers increase the most $(+27.5 \%)$, followed by commuter trips $(+24.1 \%)$. The greater changes in leisure trips compared to commuting and shopping might be due to the fact that leisure travel is more spontaneous in nature.

For commuting, trips by e-bike clearly challenge the dominance of car trips. The car mode share drops from $76.3 \%$ to $50.8 \%$. Cbikes drop 8.9 percentage points in the overall mode share, but this means nearly a $100 \%$ reduction in c-bike usage. The before and after dynamics of changes in shopping trips are similar to commuter trips. Following car, e-bike is the second main mode for shopping purposes (41\%) in T1. The reduction in car share is more significant for commuting and shopping trips than that for leisure. C-bike kilometer is significantly reduced for most of the trip purposes.

\subsection{The "green" shifters}

As shown in the analysis above, the modal shift patterns of new e-bikers give a mixed picture at an aggregated level. We now investigate which segments of e-bikers are more likely to reduce their car use after acquiring an e-bike.

To do so, we analyze the change in car usage from T0 to T1, incorporating various socio-demographic factors in a linear regression model. The most relevant change regarding sustainability is in the car $\mathrm{km}$ traveled. We define the dependent variable as the 
difference between a participant's car km share at T0 and at T1. A negative value means the car share drops after e-bike adoption. Conversely, a positive value indicates an increase in car mode share at T1. For the independent variables, since research has proven that social-demographic characteristics influence travel behavior, we take the following factors into account: gender, age, educational level, employment status, urban density, household size, household car ownership, and average trip distance.

As the demographics do not change much over the course of one year, we use the values at year T1 in the model. All categorical variables are dummy coded. The final model includes three variables: age, urban density, and average trip distance, which are statistically significant (Table 7).

The results indicate that age groups 25-39y, 40-49y and 60-69y seem more likely to reduce their car use (both as driver and as passenger) after adopting an e-bike, than the 50-59y group. Regarding urban density, people living in highly urbanized areas tend to be less likely to reduce their car use after adopting an e-bike than new e-bikers in non-urbanized areas. Finally, a comparison of trip distances shows that the longer the average trip, the more likely people will continue to use a car after acquiring an e-bike.

\section{Discussion}

By examining a group of e-bikers' travel behavior before and after adopting an e-bike, this study provides a better understanding of the overall modal shift and detailed travel change patterns in trip distances and purposes. Regarding environmental implications, we identify the "green" shifters who are more likely to reduce their car use after acquiring an e-bike.

Our findings indicate that after e-bike adoptions, c-bike use reduces significantly, while car use reduces less strongly. The reduction in car use is prominent as a car driver, but not so much as a car passenger. Nevertheless, this is only part of the modal shift story. We also need to consider the large share of car $\mathrm{km}(59.6 \%)$ and the c-bike's relatively small share (20.3\%) at the baseline. Regarding the changes in modal split, the car mode share and c-bike share drop by 9.6 and 18.2 percentage points respectively. In addition, the car's emission rate is several times higher than that of an e-bike's per passenger kilometer (Cherry et al., 2009). This thus implies a net positive environmental gain after people adopt an e-bike.

These results need to be interpreted carefully, bearing in mind the local context. As discussed in the literature review, e-bikes are more likely to substitute the dominant modes in a given mobility system. In the Netherlands, cars and c-bikes constitute the two largest shares of the modal split. It is thereby generally intuitive that e-bike adoption is followed by the biggest drop in car and c-bike kilometers. In this sense, our research results are consistent with the existing literature. These positive environmental implications, however, may not be generalized to other countries with a different local mobility context.

Although many prior studies investigated the modal shift effects of e-bikes at the aggregated level, hardly any study has explored at a disaggregated level the profile of e-bikers who are more likely to reduce their car use. Our study is thus innovative in this explorative endeavor. The finding that people younger than 50 and those around retirement age (60-69) seem to be more likely to get out of their cars than the 50-59 age group, could possibly be because people younger than 50 have more physical strength to switch from cars to alternative modes. Adopting a more active mode of travel may be one motivation for them to purchase an e-bike in the first place (Plazier et al., 2017; Popovich et al., 2014). The 50-59 age group may experience more physical constraints to cycling longer distances as they get older. As people in the 60-69 age group find their physical fitness diminishing, we would expect little change in their car use. Yet the results indicate that this age group is more likely to reduce their car use compared to the younger 50-59 group. In the Netherlands, it is common for people to reduce their working hours or retire after the age of 65. Therefore, we could argue that the non-linear trend in the 60-69 group is partly due to reduced commuting needs and greater flexibility in travel times, making the shift to cycling a viable option. This corresponds with the data in Table 3 that the 50-59 age group is less active in e-bike use. The non-linear effect of age concurs with research findings by Simsekoglu and Klöckner (2018), investigating the determinants of e-bike use in groups of e-bikers and non-users. Their study shows that the likelihood of e-bike use increases up until the age of around 60 and then drops. Taking all these factors into consideration, we see that, although people younger than 50 and between 60 and 69 are less likely to start riding an e-bike, once they have access to one, they appear to be more active in e-cycling and more likely to reduce their car use.

Our finding, that people living in rural areas seem more likely to reduce car use than their counterparts in highly urbanized areas, is somewhat counter-intuitive. In general, higher density means shorter trip distances, which should make it easier to reduce car use. One explanation might be that before e-bike adoption, the car mode share is already relatively low in highly urbanized areas (78.1\% vs. $89.9 \%$ in rural areas). Thus, there is limited leeway to reduce car use further in more urbanized areas. Although both areas end up with similar car levels at T1 (68.2\% in highly urbanized areas and $67.1 \%$ in rural areas), the degree of change is greater in highly urbanized areas. Besides, as the Netherlands is one of the most densely populated countries, a rural area still means a density of around 500 addresses per square kilometer. Most trips fall between the range of 5-15 km, making the e-bike a practical travel option. Another possible explanation is that rural residents might be car-captive and that e-bikes give them a way out. Moreover, it is easier to cycle in a suburban environment than in congested big cities (Kasraian et al., 2018). A study by Plazier et al. (2017) indicates that e-bikers find it more enjoyable to cycle in sub-urban and rural areas; the dense and complex traffic situations or multiple forced stops in urban settings lead to a loss of momentum and interrupted flows for e-cycling. This implies that an e-bike can be fully utilized in suburban areas and could therefore become a viable alternative to a car. Consequently, the shift from car to e-bike is more likely to happen in rural areas than in cities.

The Netherlands is a premier cycling country, as evidenced by the fact that about one in every four trips there is by bike. However, more than $70 \%$ of passenger kilometers are traveled by car (KiM, 2016). The Dutch practice of mobility therefore still faces the challenges of reducing car use, especially for intercity trips (Sun, 2019). In addition, cycling levels in the Netherlands seem to have reached a glass ceiling, which has been more or less stable for the past decades (Harms et al., 2014). Given e-bike's position in 
between a c-bike and a car, it could potentially substitute some short and medium distance car trips. Together with c-bikes, e-bikes might just be able to break that glass ceiling.

While the present study generates new insights, we also identify some limitations. The small sample size is the main constraint, since the low number of participants limits the statistical power of calculations. Though longitudinal data presents obvious advantages by providing information for the same respondents across time, it also has the shortcomings of a small scale sample compared to cross-sectional data. Genuine panel data is also affected by the problem of participants dropping out. Consequently, the results may be subject to some random noise. As the MPN dataset is a three-day travel survey from a one-year period, our sample selection methods might oversample active users by filtering those who had made at least one e-bike trip. Nonetheless, the effect of bias towards active users is limited to some extent thanks to the following factors. MPN respondents were randomly selected, regardless of their preferred transport mode. Besides, the 3-day consecutive travel surveys were randomly chosen by each individual. The use of transport modes were also random for the respondents. Respondents who just happened to use an e-bike in the reporting period may well be inactive users the rest of the year. Conversely, those who did not use an e-bike in the period could be active users at other times of the year.

Notwithstanding the small sample size, this paper presents some interesting results which could serve as a pilot study for further research. Given the exploratory nature of the research, we suggest expanding future similar studies with a larger sample size, to improve our understanding of how e-bike adoption affects modal shifts. In addition, travel survey data lacks in-depth information such as the motivation for switching to an e-bike. It is better to seek explanations of motives and perceptions of e-bike owners in qualitative research, such as by Jones et al. (2016).

As this study assesses changes in travel behavior right after e-bike adoption, it remains to be seen whether the modal shift is only a short-term effect or will remain stable after several years. Research suggests both a novelty effect and a learning effect of e-bike use (Fyhri and Fearnley, 2015). After initially acquiring an e-bike as means of transportation, e-bikers may extensively explore and even adopt more and new ways to use it over time. The multi-year effects could in principle be explored with the MPN or similar longitudinal datasets. Partly due to the limited sample size, our study only devotes one section to the changes in car mode share. Further research with a larger sample could extend this line of inquiry to explore mode-shift models by purpose or distance, and vehicle ownership duration models. Previous studies indicate that people usually adopt e-bikes following specific life events (Plazier et al., 2017). Though this is not the focus of our research, it would be interesting for future studies to explore what life events or factors trigger the shift to e-bikes.

\section{Conclusions}

This study contributes to the debate about the environmental implications of e-bike use. Despite extensive research on the modal shift effects of e-bikes, direct evidence with ecological validity is lacking. Our endeavor is thus unique in directly assessing the change in the before and after travel behavior of actual e-bike users who take part in a panel survey. Moreover, at a disaggregated level, this research sheds light on the profile of those people who are more likely to reduce their car use after acquiring an e-bike. We also discover how factors such as age, urban density, and average trip distance impact e-bikers' tendency to reduce car use. Our results show, that thanks to e-bikes, passenger transport in the Netherlands is experiencing a sustainable shift.

This study raises several policy implications: First, promoting e-bikes in the Netherlands can achieve a net gain in environmental sustainability. Second, in order to reap the greatest environmental benefits, e-bike promotion policies could target young age groups and those around retirement age, as well as people living in rural areas. Third, to facilitate a greener modal shift in cities, policies should aim to improve cycling conditions by smoothening the flow for cyclists, while calming car traffic. In this way, the e-bike can achieve its full potential and be a truly competitive alternative to the car.

\section{CRediT authorship contribution statement}

Qi Sun: Conceptualization, Methodology, Investigation, Formal analysis, Visualization, Writing - original draft, Writing - review \& editing. Tao Feng: Formal analysis, Writing - review \& editing. Astrid Kemperman: Formal analysis, Writing - review \& editing. Andreas Spahn: Supervision, Writing - review \& editing.

\section{Acknowledgements}

This article uses data from the Netherlands Mobility Panel, administered by the Netherlands Institute for Transport Policy Analysis (KiM). The authors would like to thank Lucas Harms, Sascha Hoogendoorn-Lanser, and Mathijs de Haas for their help with MPN data. We are also grateful to XU Juan, Elena Mas Tur, Emilio Raiteri, and ZHANG Chao for their advice on statistical analysis.

This work was supported by the "Bicycle Challenges: Past, Present, and Future" project, funded by Eindhoven University of Technology, PON Holding, and The Dutch Public Works Administration. The principle investigator of the project is Professor Ruth Oldenziel at Eindhoven University of Technology, School of Innovation Sciences, Department of Technology, Innovation, and Society, see http://www.cyclingcities.info/research/phd-program-tue/

\section{Appendix A. Supplementary material}

Supplementary data to this article can be found online at https://doi.org/10.1016/j.trd.2019.102202. 


\section{References}

Buehler, R., Pucher, J., Merom, D., Bauman, A., 2011. Active travel in Germany and the U.S.: contributions of daily walking and cycling to physical activity. Am. J. Prev. Med. 41, 241-250. https://doi.org/10.1016/j.amepre.2011.04.012.

Cairns, S., Behrendt, F., Raffo, D., Beaumont, C., Kiefer, C., 2017. Electrically-assisted bikes: Potential impacts on travel behaviour. Transp. Res. Part Policy Pract. 103, 327-342. https://doi.org/10.1016/j.tra.2017.03.007.

Cervero, R., Sarmiento, O.L., Jacoby, E., Gomez, L.F., Neiman, A., 2009. Influences of built environments on walking and cycling: lessons from bogotá. Int. J. Sustain. Transp. 3, 203-226. https://doi.org/10.1080/15568310802178314.

Cherry, C., Cervero, R., 2007. Use characteristics and mode choice behavior of electric bike users in China. Transp. Policy 14, 247-257. https://doi.org/10.1016/j. tranpol.2007.02.005.

Cherry, C.R., Weinert, J.X., Xinmiao, Y., 2009. Comparative environmental impacts of electric bikes in China. Transp. Res. Part Transp. Environ. 14, 281-290. https:// doi.org/10.1016/j.trd.2008.11.003.

Cherry, C.R., Yang, H., Jones, L.R., He, M., 2016. Dynamics of electric bike ownership and use in Kunming. China. Transp. Policy 45, 127-135. https://doi.org/10. 1016/j.tranpol.2015.09.007.

Electric Bikes Worldwide Reports, 2016. URL http://www.ebwr.com/.

European Commission, 2016. EU transport in figures 2016. Publications Office of the European Union, Luxembourg.

European Commission, 2017. Retrieved from https://ec.europa.eu/clima/policies/transport/vehicles/cars_en\#tab-0-3.

Eurostat, 2017. Retrieved from http://ec.europa.eu/eurostat/statistics-explained/index.php?title=Climate_change_-_driving_forces\&oldid=348513.

Fishman, E., Cherry, C., 2016. E-bikes in the mainstream: reviewing a decade of research. Transp. Rev. 36, 72-91. https://doi.org/10.1080/01441647.2015.1069907.

Fyhri, A., Fearnley, N., 2015. Effects of e-bikes on bicycle use and mode share. Transp. Res. Part Transp. Environ. 36, 45-52. https://doi.org/10.1016/j.trd.2015.02. 005.

Fyhri, A., Heinen, E., Fearnley, N., Sundfør, H.B., 2017. A push to cycling-exploring the e-bike's role in overcoming barriers to bicycle use with a survey and an intervention study. Int. J. Sustain. Transp. 11, 681-695. https://doi.org/10.1080/15568318.2017.1302526.

Garrard, J., Rose, G., Lo, S.K., 2008. Promoting transportation cycling for women: The role of bicycle infrastructure. Prev. Med. 46, 55-59. https://doi.org/10.1016/j. ypmed.2007.07.010.

Harms, L., Bertolini, L., te Brömmelstroet, M., 2014. Spatial and social variations in cycling patterns in a mature cycling country exploring differences and trends. J. Transp. Health 1, 232-242. https://doi.org/10.1016/j.jth.2014.09.012.

Haustein, S., Møller, M., 2016. Age and attitude: Changes in cycling patterns of different e-bike user segments. Int. J. Sustain. Transp. 10, 836-846. https://doi.org/10. $1080 / 15568318.2016 .1162881$.

Heinen, E., van Wee, B., Maat, K., 2010. Commuting by bicycle: an overview of the literature. Transp. Rev. 30, 59-96. https://doi.org/10.1080/01441640903187001.

Hoogendoorn-Lanser, S., Schaap, N.T.W., OldeKalter, M.-J., 2015. The Netherlands mobility panel: an innovative design approach for web-based longitudinal travel data collection. Transp. Res. Procedia 11, 311-329. https://doi.org/10.1016/j.trpro.2015.12.027.

Johnson, M., Rose, G., 2013. Electric bikes-cycling in the New World City: an investigation of Australian electric bicycle owners and the decision making process for purchase. Proceedings of the 2013 Australasian Transport Research Forum.

Jones, T., Harms, L., Heinen, E., 2016. Motives, perceptions and experiences of electric bicycle owners and implications for health, wellbeing and mobility. J. Transp. Geogr. 53, 41-49. https://doi.org/10.1016/j.jtrangeo.2016.04.006.

Kasraian, D., Maat, K., van Wee, B., 2018. Urban developments and daily travel distances: Fixed, random and hybrid effects models using a Dutch pseudo-panel over three decades. J. Transp. Geogr. 72, 228-236. https://doi.org/10.1016/j.jtrangeo.2018.09.006.

KiM, 2016. Mobility Report. Netherlands Institute for Transport Policy Analysis.

Krizek, K.J., Handy, S.L., Forsyth, A., 2009. Explaining changes in walking and bicycling behavior: challenges for transportation research. Environ. Plan. B Plan. Des. 36, 725-740. https://doi.org/10.1068/b34023.

Kroesen, M., 2017. To what extent do e-bikes substitute travel by other modes? Evidence from the Netherlands. Transp. Res. Part Transp. Environ. 53, 377-387. https://doi.org/10.1016/j.trd.2017.04.036.

Lee, A., Molin, E., Maat, K., Sierzchula, W., 2015. Electric bicycle use and mode choice in the Netherlands. Transp. Res. Rec. J. Transp. Res. Board 2520, 1-7. https:// doi.org/10.3141/2520-01.

Ling, Z., Cherry, C.R., Yang, H., Jones, L.R., 2015. From e-bike to car: A study on factors influencing motorization of e-bike users across China. Transp. Res. Part Transp. Environ. 41, 50-63. https://doi.org/10.1016/j.trd.2015.09.012.

MacArthur, J., Cherry, C., Harpool, M., Schepke, D., 2018. Electric boost: insights from a national E-bike owner survey. Transport. Res. Educ. Center. https://doi.org/ 10.15760/trec.197.

Plazier, P.A., Weitkamp, G., van den Berg, A.E., 2017. “Cycling was never so easy!” An analysis of e-bike commuters' motives, travel behaviour and experiences using GPS-tracking and interviews. J. Transp. Geogr. 65, 25-34. https://doi.org/10.1016/j.jtrangeo.2017.09.017.

Popovich, N., Gordon, E., Shao, Z., Xing, Y., Wang, Y., Handy, S., 2014. Experiences of electric bicycle users in the Sacramento, California area. Travel Behav. Soc. 1, 37-44. https://doi.org/10.1016/j.tbs.2013.10.006.

Simsekoglu, Ö., Klöckner, C.A., 2018. The role of psychological and socio-demographical factors for electric bike use in Norway. Int. J. Sustain. Transp. 1-9.

Sun, Q., 2019. Barriers and Facilitators to Cycling in European Cities: a Comparative Case Study of Cycling in London and Amsterdam. In: Grafl, K., Schulz, C. (Eds.). Paper presented at the Proceedings of the International Cycling Conference, 19-21 September 2017, Mannheim, Germany. pp.19. Retrieved from https://www. umweltbundesamt.de/publikationen/international-cycling-conference-2017.

Van Acker, V., Van Wee, B., Witlox, F., 2010. When transport geography meets social psychology: toward a conceptual model of travel behaviour. Transp. Rev. 30, 219-240. https://doi.org/10.1080/01441640902943453.

Weiss, M., Dekker, P., Moro, A., Scholz, H., Patel, M.K., 2015. On the electrification of road transportation ? A review of the environmental, economic, and social performance of electric two-wheelers. Transp. Res. Part Transp. Environ. 41, 348-366. https://doi.org/10.1016/j.trd.2015.09.007.

Winslott Hiselius, L., Svensson, A., 2014. Could the increased use of e-bikes (pedelecs) in Sweden contribute to a more sustainable transport system? Vilnius Gediminas Technical University Press “Technika" 2014. https://doi.org/10.3846/enviro.2014.119.

Wolf, A., Seebauer, S., 2014. Technology adoption of electric bicycles: A survey among early adopters. Transp. Res. Part Policy Pract. 69, 196-211. https://doi.org/10. 1016/j.tra.2014.08.007. 